\title{
Evaluation of Uncertainty in Angle Measurement performed on a Coordinate Measuring Machine
}

\author{
Rajamani R, Vignesh R, Mouliprasanth $\mathrm{B}^{1}$ \\ \{rajamani.vrr@gmail.com, vigneshrethinam29@gmail.com, bmouliprasanth@gmail.com ${ }^{1}$ \} \\ Department of Production Engineering, PSG College of Technology, Coimbatore, India, Department \\ of Manufacturing Engineering, College of Engineering Guindy, Chennai, India ${ }^{1}$
}

\begin{abstract}
Coordinate Measuring Machine (CMM) is a universally accepted instrument that is widely used for inspection in industries and laboratories. Evaluation of uncertainty in dimensional measurement is very important for any measurement process. The components and the parts of the mechanical systems must have the accurate dimensions to meet the functional requirements. The environmental conditions and measurement methodhighly influence the accuracy of measurement process.This paper focuses on estimating the uncertaintyin angle measurementscarried out using CMM. In this study, anglegauge blocks are used as the reference materials for assessing the uncertainty in measurement using a CMM. An uncertainty estimation is carried out according to the guide to the expression of uncertainty in measurement (GUM). The influence of position accuracy, environment temperature, vibration, measurement and probing strategies are analysed and uncertainty in angle measurement is estimated as 40 arc seconds.
\end{abstract}

Keywords: Coordinate measuring machine, uncertainty estimation, angle measurement, GUM.

\section{Introduction}

Inspection of part dimensions and geometric features are integrated with the manufacturing processes. In manufacturing industries, Coordinate Measuring Machine are mostly used for inspecting the Geometric Dimensioning \&Tolerancing (GD\&T) features of semi-finished and finished components. Tomeet the growing demands of tight tolerances in part dimensions computerized inspection systems are widely used in the industries. All the measuring processes have some quantification of doubt about the measurement result which is termed as uncertainty in measurement. Uncertainty value should be taken into account with all measurements without which, the measurement result is only an approximate value of the measured.

Measuring process is divided into direct and indirect measurement processes. Indirect measurement processes require certain algorithms to get the measured values. Coordinate measuring machine is one of the popular inspection devices that give more accurate and precise results by indirect method. The coordinate points of mechanical parts are recorded quickly and accurately using CMM. The desired features are then measured with the help of CMM software. Even though it gives better results, many factors influence the measurement accuracy of CMM such as hardware error, environmental temperature, vibration and 
evaluation strategy etc. Hence it is essential to consider the measurement uncertainty for an efficient measurement by CMM.

Many studies are available for analysis of form features, parameter influencing the CMM measurement, angle measurement strategies and uncertainty evaluation in CMM. Some of these are discussed in this section. An extensive study on the influence of form deviations in uncertainty measurement was clearly presented by Choi et al.[1] and Jack et al.[2]. Amato et al.[3] presented the indirect measurement of angles and evaluation of uncertainty using CMM. A Monte Carlo simulation method was used for error analysis by many investigators [4], [5] and [6]. Gyula Hermann[7] developed an algorithm for geometric error correction in coordinate measurement. Sartori et al.[8]established a method to compensate the thermal effect during measurement in CMM. Bourdet et al.[9] conducted experiments to locate the best fit sphere using data point distribution and statistical model.Gaska et al. [10] presented a method to estimate the uncertainty of five axis measuring system using virtual models and results of virtual model are validated with the experimental results.

Ito et al. [11] proposed a new method to calculate the form error of a probe tip ball. Uncertainty due to form error of probe ball is estimated as less than $0.5 \mu \mathrm{m}$.Patricio [12] analysed the effect of position error, random error and straightness error on accuracy of CMM. The study shows that the random error can be neglected when the straightness error of the CMM is less than one micrometer.

Branko[13] investigated the effect of environment temperature on measurement uncertainty in CMM measurements and results show that temperature has significant effect dimensional measurement and less effect on roundness measurement.Płowucha[14]presented a point to straight line distance model to evaluate the measurement uncertainty using CMM. Senin et al. [15]proposed a statistical model with of Monte Carlo simulation to estimate the measurement uncertainty in coordinate measuring system.

From the literature, it is obvious that quantification of error is inevitable in any measuring process. In this paper, a systematic study is carried out to estimate uncertainty in angle measurementperformed on a CMM and angle gauges are used as a reference standard. To evaluate the uncertainties, coordinate points of angle gauges are recorded andedges of gauges are constructed using a least square algorithmthen the angle between the edges are calculated. Finally, the results are presented in the form of uncertainty budget and expanded uncertainty.

Uncertainty in Measurement

Uncertainty is the suspicion concerning the measurement result which means the lack of true value of measurand. The reasons for the errors are sources like hardware, environmental temperature, vibration, measurement methods and work pieces. Though CMM measure the parts precisely, uncertainty needs to be evaluated in CMM. Some of the sources which affect the measuring results are shown in Fig.1.

A. Hardware

Hardware errors arise from the inherent design of the machine, its scale, probing system and the place where the machine is placed.

\section{B. Environment}

The environmental condition of CMM is an important source of uncertainty measurement. Due to change in temperatures, machine structure / component to be inspected will elongate or contract. This affects the measurement accuracy. To minimize the error due to thermal effects the part to be measured are held in the laboratory environment for a few hoursbefore measurement. The other machines which are installed near the CMM will make the floor vibration and that will affect the results of CMM. So, preventive activity has to be taken before inspection. 


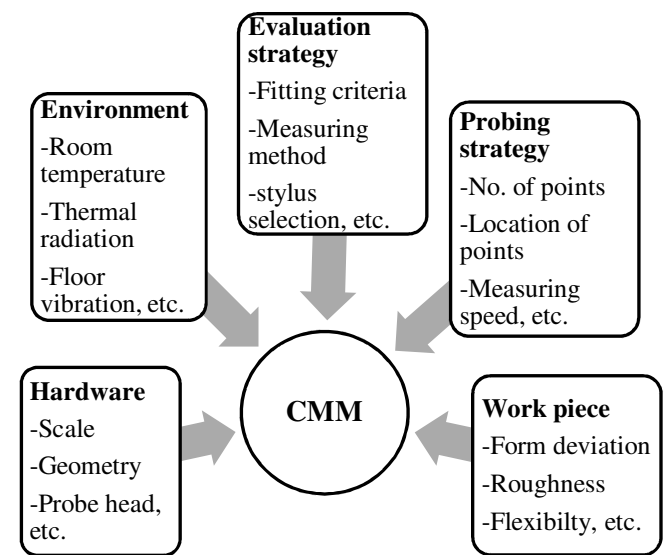

C. Evaluation Strategy

Fig. 1. Sources of uncertainty

Different measuring methods and fitting criteria are used to measure the measurand in CMM and each method differs from the others. So, this may lead to error in measured results. Other factors like selection of algorithm, filtering method etc. also affect the results.

D. Probing strategy

This source of uncertainty depends on the position in which coordinate points are measured, number of measuring points and measuring speed. Probing strategy will play a role on measuring results.

C. Work piece

Measurand is a one of the important sources of uncertainty in measurement. Due to the form deviation and surface imperfections, the measurement results may vary. In this work, five potential sources of uncertainties are evaluated which will influence the angle measurement. The sources of uncertainties are found to be calibration, probing error, reading error and temperature effect.

\section{Experimental Work}

\section{A. CMM and Angle Gauges}

The CMM machine used for this study is a moving bridge CMM, Carl Zeiss CONTURA G2 RDS $(700 \mathrm{~mm} \times 1000 \mathrm{~mm} \times 600 \mathrm{~mm})$. The complete measuring system was maintained at the controlled temperature $\left(20 \pm 1^{\circ} \mathrm{C}\right)$. Brown \& Sharp Steel angle gauge blocks are used as a measurand which has nominal angle values of $1^{\circ}, 3^{\circ}, 5^{\circ}, 10^{\circ}, 15^{\circ}, 30^{\circ}$. The angular accuracy of the gauge is $0.0003^{\prime \prime}$ and uncertainty considered for the experiments is \pm 30 arc second. Fig.2 shows the measurement setup with angle gauges and magnetic V Block. 


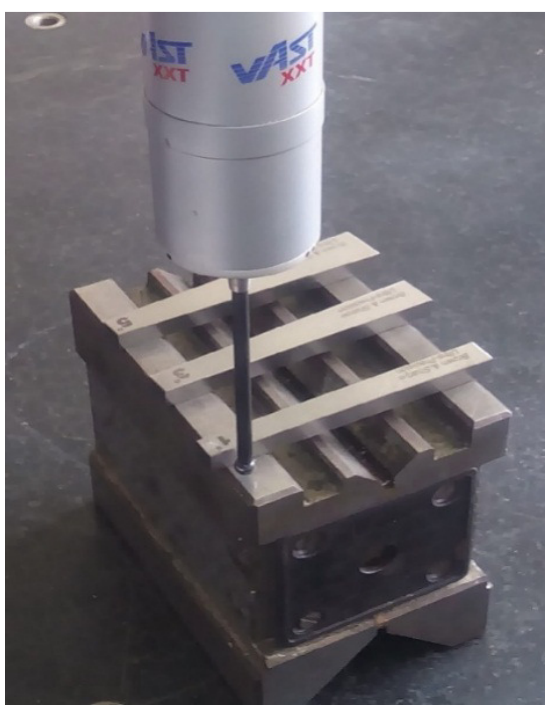

Fig. 2. Measuring Setup.

For measuring the angle, gauge blocks are fixed on a magnetic V-block and datum has been set up that is necessary for taking the coordinate points on the angle gauge blocks. The possible errors that may occur during the measurement process are shown in Fig.3. The angle between the indicated and the reference plane is measured using the $3 \mathrm{~mm}$ diameter probe.

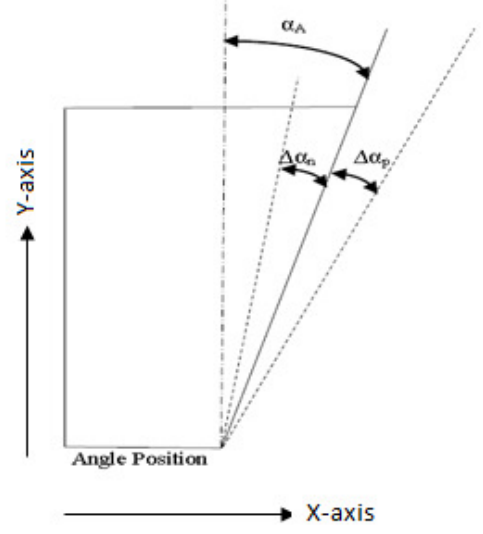

Fig. 3. Gauge value $(\alpha \mathrm{A})$, positive error $\left(\Delta \alpha_{\mathrm{p}}\right)$ and negative error $\left(\left(\Delta \alpha_{n}\right)\right.$.

In this process, coordinate points and measurement results are obtained by absolute control mode and incremental control mode using the control panel. Through the coordinate points (Absolute control mode), angle value is calculated using a linear least square algorithm. Mathematical representation of distance between the points is given in (1)

$$
L=\sqrt{\left(x_{2}-x_{1}\right)^{2}+\left(y_{2}-y_{1}\right)^{2}+\left(z_{2}-z_{1}\right)^{2}}(1)
$$

Angle between two points are given by (2), (3) and (4) 


$$
\begin{aligned}
\cos \alpha & =\frac{x_{2}-x_{1}}{L} \\
\cos \beta & =\frac{y_{2}-y_{1}}{L} \\
\cos \gamma & =\frac{z_{2}-z_{1}}{L}
\end{aligned}
$$

Where $\mathrm{L}$ is a distance between two points, $\alpha, \beta$ and $\gamma$ are angle between two points and $\mathrm{x}$, $\mathrm{y} \& \mathrm{z}$ are the coordinate points.

The result obtained from CMM are compared with the reference values that gives the error in measurement. Then the error sources such as calibration error, probing error, reading error, error due to temperature and linear error are studied and finally uncertainty of CMM is calculated using GUM method.

C. Deviation in angle measurement by CMM Calibration

Thecoordinate points of the edges of slip gauge are recordedand measured values of the angle gauge are read from the CMM software. The CMM software (CALYPSO) usesthe nonlinear least square method for constructing the best fit line then the angle between the lines are measured. Table 1 shows the actual value, measured value and deviation taken from the CMM software.

Table 1. Angle deviation in CMM calibration

\begin{tabular}{|l|l|l|c|}
\hline Sl. No & $\begin{array}{l}\text { Angle gauge } \\
\text { value }\end{array}$ & $\begin{array}{l}\text { Measured } \\
\text { value }\end{array}$ & Deviation \\
\hline 1 & $1^{\circ}$ & $0^{\circ} 59^{\prime} 16^{\prime \prime}$ & $-0^{\circ} 0^{\prime} 44^{\prime \prime}$ \\
\hline 2 & $1^{\circ}$ & $0^{\circ} 59^{\prime} 56^{\prime \prime}$ & $-0^{\circ} 0^{\prime} 4^{\prime \prime}$ \\
\hline 3 & $1^{\circ}$ & $0^{\circ} 59^{\prime} 51^{\prime \prime}$ & $-0^{\circ} 0^{\prime} 9^{\prime \prime}$ \\
\hline 4 & $1^{\circ}$ & $1^{\circ} 0^{\prime} 42^{\prime \prime}$ & $0^{\circ} 0^{\prime} 42^{\prime \prime}$ \\
\hline 5 & $3^{\circ}$ & $2^{\circ} 59^{\prime} 44^{\prime \prime}$ & $-0^{\circ} 0^{\prime} 16^{\prime \prime}$ \\
\hline 6 & $3^{\circ}$ & $3^{\circ} 0^{\prime} 14^{\prime \prime}$ & $0^{\circ} 0^{\prime} 14^{\prime \prime}$ \\
\hline 7 & $3^{\circ}$ & $2^{\circ} 59^{\prime} 58^{\prime \prime}$ & $-0^{\circ} 0^{\prime} 2^{\prime \prime}$ \\
\hline 8 & $5^{\circ}$ & $5^{\circ} 0^{\prime} 50^{\prime \prime}$ & $0^{\circ} 0^{\prime} 50^{\prime \prime}$ \\
\hline 9 & $5^{\circ}$ & $4^{\circ} 59^{\prime} 52^{\prime \prime}$ & $-0^{\circ} 0^{\prime} 8^{\prime \prime}$ \\
\hline 10 & $5^{\circ}$ & $5^{\circ} 0^{\prime} 11^{\prime \prime}$ & $0^{\circ} 0^{\prime} 11^{\prime \prime}$ \\
\hline
\end{tabular}

The CMM uncertainty has been calculated using GUM method which is explained in the next section. Standard uncertainty value and expanded uncertainty value are indicated in Table.2.

\section{Results and discussions}

GUM method is followed to estimate uncertainty in measurement. Angle measurement model considered in this studyis expressed asfollows[15]

$Y=X+K_{C A L}+K_{P R O B}+K_{R E A D}+K_{T E M P}+K_{L}$

Where $\mathrm{X}$ is a measured angle value, $K_{C A L}$ is the calibration error, $K_{P R O B}$ is probing error, $K_{R E A D}$ is the reading error, $K_{T E M P}$ is temperature difference and $K_{L}$ is the distance error.

Combined uncertainty is evaluated based on law of propagation of uncertainty as expressed in (6):

$$
u_{c}^{2}(y)=\sum_{i=1}^{n}\left(\frac{d f}{d x}\right)^{2} \cdot u^{2}\left(x_{i}\right)
$$


Where $u\left(x_{i}\right)$ is standard uncertainty and $d f / d x$ is sensitivity coefficient.

The combined uncertainty is expressed as:

$$
u_{c}^{2}=c_{1}^{2} \cdot u_{C A L}^{2}+c_{2}^{2} \cdot u_{P R O B}^{2}+c_{3}^{2} \cdot u_{R E P}^{2}+C_{4}^{2} \cdot u_{T E M P}^{2}+\quad c_{5}^{2} \cdot u_{L}^{2}
$$

Where $u_{C A L}$ is uncertainty due to uncertainty of CMM calibration, $u_{P R O B}$ is uncertaintydue to probing error, $u_{R E P}$ is the uncertainty due to repeatability, $u_{T E M P}$ is uncertaintydue to temperaturegradient, $u_{L}$ is uncertainty of the distance error.

Uncertainty of distance error is calculated using (11),

$$
u^{2}(L)=L^{2} \frac{E_{k}^{2}}{3}+\frac{E_{G}^{2}}{3}+\frac{R^{2}}{3}
$$

Where $E_{k}\left(\mathrm{E}_{\mathrm{K}}=\right)$ is maximum permissible measuring error of measuring volume $=(1.8+$ $\left.\frac{L}{300}\right) \mu \mathrm{m}$ and $E_{G}$ is maximum permissible probing error $=1.8 \mu \mathrm{m}$ and Ris the resolution of the $\mathrm{CMM}=0.2 \mu \mathrm{m}$.

Uncertainty due to calibration error is expressed as,

$u_{C A L}=\frac{U_{C A L}}{k}$

Where $U_{C A L}$ is expanded uncertainty of calibration error with coverage factor $k=1.96$, for $95 \%$ confidence level.

Uncertainty of probing error is expressed as,

$u_{P R O B}^{2}=u_{F}^{2}$

Where $u_{F}$ is uncertainty of workpiece error.

The uncertainty due to repeatability is expressed as,

$u_{R E P}^{2}=\sqrt{\frac{\sigma^{2}}{n}}$

Where $\sigma$ is the standard deviation of the readings.

The standard uncertainty due to resolution of thermometer is calculated as,

(12)

$$
u_{\text {resol }}=\frac{\text { resolution } x \text { thermal coefficient } X \text { gauge length }}{\sqrt{3}}
$$

The sensitivity coefficient expressed as the partial derivative of (2), (3), and (4).

$\frac{\partial(\cos \alpha)}{\partial x}, \frac{\partial(\cos \beta)}{\partial x}$ and $\frac{\partial(\cos \gamma)}{\partial x}$

Combined uncertainty has been calculated using (7). Expanded uncertainty which is expressed as,

$U=k \cdot u_{c}(y)$

Using these formulas uncertainty due to various sources of error are estimated and the results are summarized in table 2. It is observed that expanded uncertainty in angle measurement at $95 \%$ confidence level is $0.0112^{\circ}(40$ arc seconds).

Table 2. Sources of uncertainty values

\begin{tabular}{|l|l|l|l|l|}
\hline $\begin{array}{l}\text { Uncertainty } \\
\text { sources }\end{array}$ & $\begin{array}{l}\text { Standard } \\
\text { uncertainty } \\
\text { values }(\mathbf{m m})\end{array}$ & $\begin{array}{l}\text { Probability } \\
\text { distribution }\end{array}$ & $\begin{array}{l}\text { Sensitivity } \\
\text { coefficient }\end{array}$ & $\begin{array}{l}\text { Uncertainty } \\
\text { value }\left(^{\circ}\right)\end{array}$ \\
\hline Calibration & $3.2 \times 10^{-3}(\mathrm{~mm})$ & normal & $1.6 \times 10^{-2}(\% / \mathrm{mm})$ & $5.12 \times 10^{-5}$ \\
\hline Probing error & $1.8 \times 10^{-3}(\mathrm{~mm})$ & normal & $1.6 \times 10^{-2}(\% / \mathrm{mm})$ & $2.88 \times 10^{-5}$ \\
\hline
\end{tabular}




\begin{tabular}{|l|l|l|l|l|}
\hline Repeatability & $5.17 \times 10^{-3}\left({ }^{\circ}\right)$ & normal & 1.0 & $5.17 \times 10^{-3}$ \\
\hline $\begin{array}{l}\text { Resolution of } \\
\text { thermometer }\end{array}$ & $8.76 \times 10^{-2}(\mathrm{~mm})$ & rectangular & $1.6 \times 10^{-2}(\% \mathrm{~mm})$ & $1.40 \times 10^{-3}$ \\
\hline $\begin{array}{l}\text { Temperature } \\
\text { (Avg. std. \&Avg. } \\
\text { room temp) }\end{array}$ & $5.09 \times 10^{-2}$ & rectangular & $1.6 \times 10^{-2}(\% / \mathrm{mm})$ & $8.144 \times 10^{-4}$ \\
\hline $\begin{array}{l}\text { Temperature } \\
\text { (CMM \&gauge) }\end{array}$ & $8.76 \times 10^{-2}(\mathrm{~mm})$ & rectangular & $1.6 \times 10^{-2}(\% \mathrm{~mm})$ & $1.40 \times 10^{-3}$ \\
\hline Distance & $7.17 \times 10^{-2}(\mathrm{~mm})$ & rectangular & $1.6 \times 10^{-2}(\% / \mathrm{mm})$ & $1.14 \times 10^{-3}$ \\
\hline \multicolumn{4}{|l|}{ Combined uncertainty $(\mathrm{k}=1)$} & $5.71 \times 10^{-3}$ \\
\hline \multicolumn{2}{|l|}{ Expanded uncertainty at $95 \%$ confidence level $(\mathrm{K}=1.96)$} & $\mathbf{1 . 1 2 \times 1 0 ^ { - 2 }}$ \\
\hline
\end{tabular}

\section{Conclusions}

Expanded uncertainty in angle measurement is calculated using CARL ZEISS CONTURA G2 RDS CMM according to the series standards ISO 10360 and GUM guide. In this work angle gauge blocks are used as a reference material. Angle deviationsfrom the CMMreadings and gauge blocks reference value are calculated. Standard uncertainty is calculated using the repeated measurements.Then the calibration error, probing error, reading error andtemperature gradient are considered as sources of error in CMM measurement. Using the GUM method, the combined uncertainty is evaluated.

Expanded uncertainty in angle measurements iscalculated for $95 \%$ confidence level (coverage factor, $\mathrm{k}=1.96$ ). Expanded uncertainty is found to be 40 arc seconds. In this scenario, the larger uncertainty is arisen from the repeatability error. So,uncertainty measurement should be evaluated periodically.This work focusses on a few sources of errors foruncertainty estimation and other sources of error can also be included in the uncertainty estimation.

\section{References}

[1] W. Choi, T. R. Kurfess, and J. Cagan, "Sampling uncertainty in coordinate measurement data analysis," Precis. Eng., vol. 22, no. 3, pp. 153-163, 1998.

[2] C.-X. J. Feng, A. L. Saal, J. G. Salsbury, A. R. Ness, and G. C. Lin, "Design and analysis of experiments in CMM measurement uncertainty study," Precis. Eng., vol. 31, no. 2, pp. 94-101, 2007.

[3] R. D'Amato, J. Caja, P. Maresca, and E. Gómez, "Use of coordinate measuring machine to measure angles by geometric characterization of perpendicular planes. Estimating uncertainty," Measurement, vol. 47, pp. 598606, 2014.

[4] M. Miranda and B. V. Dorrío, "Monte Carlo based techniques of two-stage phase shifting algorithms," Opt. Lasers Eng., vol. 49, no. 3, pp. 439-444, 2011.

[5] J.-P. Kruth, N. Van Gestel, P. Bleys, and F. Welkenhuyzen, "Uncertainty determination for CMMs by Monte Carlo simulation integrating feature form deviations," CIRP Ann., vol. 58, no. 1, pp. 463-466, 2009.

[6] H. Schwenke, B. R. L. Siebert, F. Wäldele, and H. Kunzmann, "Assessment of uncertainties in dimensional metrology by Monte Carlo simulation: proposal of a modular and visual software," CIRP Ann., vol. 49, no. 1, pp. 395-398, 2000.

[7] G. Hermann, "Geometric error correction in coordinate measurement," Acta Polytech. Hung., vol. 4, no. 1, pp. 47-62, 2007.

[8] P. C. Cresto, M. Di Ciommo, T. Kancheva, D. Marques, V. Mudronja, and S. Sartori, "A method for the identification and correction of thermal deformations in 3-D CMMs," Measurement, vol. 9, no. 1, pp. 38-43, 1991. 
[9] D. R. Meredith, "Vibration isolation treatments for coordinate measuring machines," in Inter-Noise 96 (Noise control: the next 25 years, Liverpool, 30 July-2 August 1996), 1996, pp. 1557-1560.

[10] P. Gąska, A. Gąska, J. Sładek, and J. Jędrzejewski, "Simulation model for uncertainty estimation of measurements performed on five-axis measuring systems," Int. J. Adv. Manuf. Technol., vol. 104, no. 9, pp. 4685-4696, 2019.

[11] S. Ito, D. Tsutsumi, K. Kamiya, K. Matsumoto, and N. Kawasegi, "Measurement of form error of a probe tip ball for coordinate measuring machine (CMM) using a rotating reference sphere," Precis. Eng., vol. 61, pp. 4147, 2020.

[12] P. Franco and J. Jodar, "Theoretical Analysis of Straightness Errors in Coordinate Measuring Machines (CMM) with Three Linear Axes," Int. J. Precis. Eng. Manuf., vol. 22, no. 1, pp. 63-72, 2021.

[13] B. Štrbac, B. Ačko, S. Havrlišan, I. Matin, B. Savković, and M. Hadžistević, "Investigation of the effect of temperature and other significant factors on systematic error and measurement uncertainty in CMM measurements by applying design of experiments," Measurement, vol. 158, p. 107692, 2020.

[14] W. Płowucha, "Point-straight line distance as model for uncertainty evaluation of coordinate measurement," Measurement, vol. 135, pp. 83-95, 2019, doi: https://doi.org/10.1016/j.measurement.2018.11.008.

[15] N. Senin, S. Catalucci, M. Moretti, and R. K. Leach, "Statistical point cloud model to investigate measurement uncertainty in coordinate metrology," Precis. Eng., vol. 70, pp. 44-62, 2021.

[16] J. C. for G. in Metrology, "Evaluation of measurement data-guide to the expression of uncertainty in measurement," JCGM, vol. 100, no. 2008, pp. 1-116, 2008. 